\title{
Sonhos de preceptores para um programa de residência multiprofissional: Utopias a
}

\section{serem investidas?}

\author{
Dreams of preceptors for a multiprofessional residency program: Utopias to be invested? \\ Sueños de preceptores para un programa de residencia multiprofesional: ¿Utopías para invertir?
}

Cristiane Trivisiol Arnemann

ORCID: https://orcid.org/0000-0003-2684-3068

Universidade Federal de Santa Maria, Brasil E-mail: cris.trivisiol@gmail.com

Maria Henriqueta Luce Kruse

ORCID: https://orcid.org/0000-0001-5320-0629

Universidade Federal do Rio Grande do Sul, Brasil E-mail: kruse@uol.com.br

Maria Elisabeth Kleba da Silva

ORCID: https://orcid.org/0000-0002-6703-8375 Universidade Comunitária da Região de Chapecó, Brasil E-mail: 1kleba@unochapeco.edu.br Marlene Gomes Terra

ORCID: https://orcid.org/0000-0001-9402-561X

Universidade Federal de Santa Maria, Brasil

E-mail: martesm@hotmail.com.br

Amanda de Lemos Mello

ORCID: https://orcid.org/0000-0002-0485-1801

Prefeitura de Jaraguá do Sul, Brasil

E-mail: amandamello6@yahoo.com

Dariane Trivisiol da Silva

ORCID: https://orcid.org/0000-0002-2203-3335

Universidade Federal de Santa Maria, Brasil

E-mail: daritrivisiolsilva@ hotmail.com

Valquíria Toledo Souto

ORCID: https://orcid.org/0000-0001-7606-5685

Universidade Federal de Santa Maria, Brasil

E-mail: valquiriatoledo@hotmail.com

\begin{abstract}
Resumo
Objetivo: analisar os sonhos de preceptores que poderiam ser implementados, com o intuito de contribuir para o fortalecimento de um Programa de Residência Multiprofissional em Saúde (RMS). Método: nosso artigo trata-se de um Estudo Apreciativo Crítico tendo como orientação teórica a Educação Permanente em Saúde (EPS) e seus conceitos atrelados ao teórico social crítico Paulo Freire. Esta pesquisa foi desenvolvida com sete preceptores do Programa de Residência Integrada Multiprofissional do Hospital de Clínicas de Porto Alegre. Os dados foram obtidos em entrevistas e grupos de discussão através de um ciclo DSPD: Descoberta, Sonho, Planejamento e Destino, após aprovação no Comitê de Ética e Pesquisa. Resultados: com relação aos sonhos dos preceptores, nós destacamos que estes estão direcionados a valorização dos preceptores, ao aproveitamento do residente como recurso humano para o Sistema Único de Saúde (SUS), ao investimento e qualificação da estrutura pedagógica dos programas de residência e ampliação dos campos de formação do residente. Além disso, identificou-se sonhos que podem ser exequíveis por meio de iniciativas ou da intervenção de preceptores, como estimular as trocas interprofissionais e entre as diferentes ênfases dentro de um mesmo programa, ou entre diferentes programas de residência. Conclusão: observamos que os preceptores trouxeram importantes reflexões sobre suas práticas em seu espaço de trabalho em um processo dialógico, reflexivo e participativo em prol de avanços nas RMS e consequente qualificação da assistência à saúde aos usuários do SUS.
\end{abstract}

Palavras-chave: Internato não médico; Educação continuada; Preceptoria; Pesquisa apreciativa; Prática profissional.

\section{Abstract}

Objective: analyzing the dreams of preceptors that could be implemented, to contribute to the strengthening of a Multiprofessional Residency Program in Health (RPH). Method: Our article is a Critical Appreciative Study with Permanent Health Education (PHE) as theoretical orientation and its concepts linked to the critical social theorist Paulo Freire. This research was developed with seven preceptors of the Multiprofessional Integrated Residency Program of the Clinical Hospital of Porto Alegre. Data were obtained in interviews and discussion groups through a 
DSPD cycle: Discovery, Dream, Planning and Destiny, after approval by the Ethics and Research Committee. Results: relating to the dreams of the preceptors, we highlight that these are directed to the valorization of preceptors, to the use of the resident as a human resource for the Unified Health System (SUS), to the investment and qualification of the pedagogical structure of residency programs and expansion of the resident's training camps. In addition, dreams that can be feasible through initiative or the intervention of preceptors, how to stimulate interprofessional exchanges and between the different emphasis within the same program, or between different residency programs, were identified. Conclusion: We observed that the preceptors brought important reflections about their practices in their workspace in a dialogical, reflexive and participatory process, in favor of advances in RPH and consequent qualification of health care to SUS users.

Keywords: Non-medical boarding school; Continuing education; Preceptorship; Appreciative research; Professional practice.

\section{Resumen}

Objetivo: analizar los sueños de los preceptores que se podrían implementar, con el fin de contribuir al fortalecimiento de un Programa de Residencia Multiprofesional en Salud (RMS). Método: nuestro artículo es un Estudio Crítico Apreciativo con la orientación teórica de la Educación Permanente en Salud (EPS) y sus conceptos vinculados al teórico social crítico del Paulo Freire. Esta investigación se desarrolló con siete preceptores del Programa Integrado de Residencia Multiprofesional del Hospital de Clínicas de Porto Alegre. Los datos se obtuvieron en entrevistas y grupos de discusión a través de un ciclo DSPD: Descubrimiento, Sueño, Planificación y Destino, previa aprobación del Comité de Ética e Investigación. Resultados: en cuanto a los sueños de los tutores, destacamos que se dirigen a la valorización de los tutores, al uso del residente como recurso humano para el Sistema Único de Salud (SUS), a la inversión y capacitación de la estructura pedagógica de los programas de residencia y expansión de los campos de formación de residentes. Además, se identificaron sueños que podrían ser factibles a través de iniciativas o la intervención de preceptores, como el fomento de intercambios interprofesionales y entre diferentes énfasis dentro de un mismo programa, o entre diferentes programas de residencia. Conclusión: observamos que los preceptores aportaron importantes reflexiones sobre sus prácticas en su espacio de trabajo en un proceso dialógico, reflexivo y participativo a favor de los avances en la RMS y la consecuente calificación de la asistencia en salud a los usuarios del SUS.

Palabras clave: Internado no médico; Educación continua; Preceptoría; Investigación apreciativa; Practica profesional.

\section{Introdução}

As práticas de ensino e de serviço na modalidade de formação como a Residência Multiprofissional em Saúde (RMS) promovem a produção de conhecimento, a partir do cotidiano dos profissionais de saúde, assim como também possibilitam a transformação das práticas assistenciais em prol de a melhoria da qualidade do atendimento aos usuários do Sistema Único de Saúde (SUS). As RMS foram desenvolvidas com o intuito de estimular práticas e ações que respondam às demandas do SUS, criando espaços para o desenvolvimento de ações de Educação Permanente em Saúde (EPS). As RMS surgiram como possibilidade para o desenvolvimento de pesquisas sobre a realidade e o cotidiano dos serviços de saúde e de articulação destes com as instituições de ensino. Esse conjunto de atividades busca a integração entre residentes, docentes, usuários, gestores, trabalhadores e profissionais de saúde e são desenvolvidas por preceptores e tutores (Arnemann, et al., 2018).

Os preceptores, atores dessa pesquisa, são profissionais de saúde vinculados ao campo de práticas, com titulação mínima de especialista, que realizam supervisão direta das atividades práticas do residente no serviço (Brasil, 2012). São fundamentais no processo de ensino aprendizagem, pois estabelecem contato diário com as atividades práticas e teóricopráticas desenvolvidas pelo residente (Ferreira; Dantas \& Valente, 2018) estimulando a interdisciplinaridade, aproximando a equipe multidisciplinar e otimizando a integralidade do cuidado (Autonomo et al., 2015).

O preceptor se destaca nas instituições assistenciais por promover situações de aprendizagem aos residentes, fazendo com que intervenções e condutas sejam exercitadas, refletidas, transformadas e apreendidas durante o processo de formação dos profissionais, tornando a preceptoria uma prática educativa (Arnemann, et al., 2018). Nessa direção, muito tem-se refletido sobre a importância do preceptor na formação e qualificação do profissional de saúde para o SUS (Ribeiro, Firmo, Souza, Figueredo \& Pacheco, 2020), assim como para o aprimoramento da sua atuação como educador no âmbito do trabalho (Ribeiro \& Do Prado, 2014; Arnemann, 2017). O déficit na formação pedagógica favorece o surgimento de lacunas na vivência prática 
do preceptor, repercutindo no desempenho da preceptoria e, consequentemente, no processo de aprendizagem dos residentes (Girard et al., 2019).

Assumir a função de preceptor denota compromisso com uma formação diferenciada de profissionais para o SUS. É um compromisso de quem se recusa a acomodação e pode estar vendo no seu papel uma possibilidade de provocar mudanças na realidade relativas às práticas e aos serviços de saúde. Mudança essa que é movida por sonhos. Para Freire, "não há amanhã sem projeto, sem sonho, sem utopia, sem esperança, sem o trabalho de criação e desenvolvimento de possibilidades que viabilizem a sua concretização". (Freire, 2015, p. 80).

Freire (2015) destaca a Utopia não como algo impossível ou projeção de quem apenas devaneia; mas, como necessidade fundamental do ser humano, parte de sua condição social e histórica de ser em permanente constituição. Para esse autor (Freire, 1997), as concepções mecanicistas da História têm decretado a morte dos sonhos e das utopias, à medida que inferiorizam o papel do ser humano no mundo e estabelecem como papel da educação o treinamento dos educandos para o uso de técnicas e a aplicação de princípios científicos. Dessa forma, dificulta, atrofia e inibe o desenvolvimento da curiosidade, da capacidade reflexiva e criadora e, justificando sua indiferença ética e política e seu compromisso com a eficácia técnica, ingenuíza a consciência e favorece a ineficácia cidadã dos indivíduos.

Ao contrário, uma educação comprometida com o ser humano instiga nossa curiosidade reflexiva e favorece nosso papel de sujeito na produção do conhecimento e na reinvenção do mundo. Esse é um dos princípios fundamentais do próprio avanço tecnológico (ou da inovação), "preparar sujeitos críticos capazes de responder com presteza e eficácia a desafios inesperados e diversificados". (Freire, 1997, p. 677). Mais do que o treinamento técnico dos educandos, a educação tem um compromisso com os sonhos e utopias, à medida que os seres humanos são seres da opção, da decisão, da intervenção no mundo, da responsabilidade (Freire, 1997). Nesse sentido, o que se propõe neste artigo/relato é promover um debate sobre sonhos de preceptores que poderiam ser implementados, com vistas a contribuir para o fortalecimento de um Programa de Residência Multiprofissional.

Nesse trabalho avançamos a produção de conhecimento quando utilizamos uma modalidade de pesquisa que dá voz aos preceptores e os incentiva a sonhar acerca de novas práticas para a residência, residentes e para a preceptoria. Nessa perspectiva, a Pesquisa Apreciativa, adotada para o estudo, possibilitou que os preceptores refletissem sobre sonhos relacionados à suas práticas. Entendemos que há necessidade de refletir sobre qualificação e fortalecimento desses espaços pedagógicos no âmbito da saúde pública brasileira a fim de objetivar uma formação com qualificação e a adequação do perfil dos trabalhadores que atendam às necessidades do SUS (França et al., 2018).

\section{Metodologia}

Nosso estudo é caracterizado como uma Pesquisa Apreciativa, conhecida na língua inglêsa como Appreciative Inquiry. Esta metodologia tem como objetivo identificar as melhores práticas desenvolvidas e empregadas pelas pessoas que trabalham em uma instituição. Além disso, possibilita a participação e o engajamento de profissionais da área da saúde em pesquisas relacionadas à sua área de atuação, podendo ser efetivamente aplicada em múltiplas áreas de pesquisa (Arnemann, Gastaldo \& Kruse, 2017).

A Pesquisa Apreciativa foi escolhida por constituir uma abordagem metodológica que vem se destacando no cenário das pesquisas qualitativas, já que explora pontos positivos e pontos comuns desenvolvidos nos meios nos quais é utilizada, e por ser pioneira em estudos da área da saúde no Brasil (Arnemann, Gastaldo \& Kruse, 2017). Somando-se a isso, a Pesquisa Apreciativa incentiva debates reflexivos e críticos por parte dos participantes, construindo um espaço de discussão para que mudanças ocorram (Arnemann, Gastaldo \& Kruse, 2017; Cooperrider, 1986). A metodologia foi desenvolvida em quatro 
etapas que constituem um ciclo 4D: Discovery, Dream, Design e Destiny. Cada etapa foi traduzida para o português como: Descoberta, Sonho, Planejamento e Destino (DSPD).

Neste artigo, destacamos a fase dos Sonhos (Arnemann, 2017) devido ao seu objetivo central, que é analisar os sonhos dos preceptores que poderiam ser implementados no Programa de Residência Multiprofissional. A Fase dos Sonhos compreende quando as descobertas referentes às melhores práticas foram organizadas, especialmente quanto ao modo de sua implementação no futuro, oferecendo aos participantes a oportunidade de explorar coletivamente suas esperanças e seus desejos para o futuro da sua equipe ou organização (Trajkovski et al., 2013a; Trajkovski et al., 2013b). Freire (1997) destaca a relevância dos sonhos na construção do futuro, à medida que esses nos instigam a intervir e transformar a realidade. Para tanto, é necessário assumir uma atitude crítica, tomando distanciamento epistemológico da concretude em que estamos situados, por meio de sua problematização, de forma a reconhecer no presente as possibilidades de um futuro melhor, que expresse nossos sonhos e utopias. "Aceitar o sonho do mundo melhor e à ele aderir é aceitar entrar no processo de criá-lo". (Freire, 1997, p. 685).

Este estudo foi desenvolvido no Programa de Residência Integrada Multiprofissional do Hospital de Clínicas de Porto Alegre. A pesquisa contou com a participação de sete preceptores, contemplando as áreas da residência como Adulto Crítico, Atenção Cardiovascular, Atenção Integral ao Usuário de Drogas, Controle de Infecção Hospitalar e Onco Hematologia, considerando as seguintes categorias profissionais: Enfermagem, Farmácia, Fisioterapia, Educação Física e Serviço Social.

Os critérios de inclusão para a pesquisa apresentaram os seguintes requisitos: os preceptores deveriam atuar na Residência Multiprofissional com o mínimo de um ano de experiência e possuir interesse em refletir e discutir sobre EPS. Ademais, consideramos a possibilidade de participar das reuniões com, no máximo, uma falta ao longo de toda coleta de dados. Neste estudo, foram incluídos preceptores de todas as profissões, para que seja contemplado ao menos um representante de cada profissão. Os preceptores que estivessem em período de férias ou licença no período da coleta de dados foram excluídos da pesquisa.

Nesta pesquisa, a fase dos Sonhos teve como objetivo imaginar a incorporação das práticas no cenário de atuação dos preceptores e, a partir disso, descrever as possíveis estratégias que poderiam ser implementadas futuramente na Residência Multiprofissional. Neste momento, os preceptores foram convidados a imaginar como poderia ser o futuro de sua atuação em uma Residência Multiprofissional com base no desenvolvimento de descrições. Para isso, os preceptores realizaram a tarefa reflexiva anteriormente a reunião.

Inicialmente, como tarefa reflexiva preparatória para a fase do Sonho, foi proposto que os preceptores escrevessem um sonho relacionado às práticas na Residência Multiprofissional e que pensassem em uma prática que ainda não é realizada na RMS. Os participantes destacaram esta tarefa como a mais significativa no processo, pois eles puderam pensar e trazer para a reunião os desejos que gostariam que se concretizassem.

Na reunião, os preceptores foram convidados a apresentar uma síntese do seu sonho, compartilhando com o grupo suas ideias. Após a apresentação dos sonhos, os preceptores realizaram um grupo de discussão sobre as questões que expressassem as melhores formas possíveis de trabalhar as práticas de EPS: Imagine se o que vocês consideram como melhores práticas se tornassem realidade institucional. Como elas aconteceriam? Qual seria a melhor forma de propagá-las? Quais as esperanças disso se tornar realidade? Essa atividade foi realizada por meio de uma discussão em grupo sobre as questões descritas acima.

Como ferramenta para produção dos dados, realizamos grupos de discussões com os preceptores. Nos encontros promovidos, os dados eram registrados através de um áudio gravador para a obtenção das transcrições dos grupos de discussões. Além disso, utilizamos notas de campo como complementação das reuniões.

A análise de dados foi elaborada de acordo com Denzin e Lincoln (2000) e foram utilizados s seguintes etapas para o 
processo temático da análise dos dados: imersão, codificação, categorização e generalização. Para a realização do estudo, foi considerada a Resolução 466/12, do Conselho Nacional de Saúde. A pesquisa foi aprovada no Comitê de Ética e Pesquisa com parecer favorável do Certificado de Apresentação para Apreciação Ética (Caae) nº 35009014.5.0000.5327.

\section{Resultados}

Esse artigo apresenta os sonhos de um grupo de preceptores sobre práticas que possam fortalecer um Programa de RMS. Dentre essas práticas, os preceptores imaginaram sonhos possíveis para si, para os residentes e para a proposta do RMS.

Em relação aos sonhos para os próprios preceptores, eles destacaram a valorização desse papel pedagógico, especialmente em relação às questões financeiras, bem como um possível plano de carreira que fortalecesse/favorecesse a progressão profissional. Ainda, apresentaram como estratégia de valorização profissional, a possibilidade de contratação como preceptores de campo:

Uma maior valorização dos preceptores quanto a questão financeira mesmo, como ocorre em algumas outras residências. Eu acho que sim, valorização financeira, porque é mais trabalho, e eu acho que a gente precisa ser remunerada por isso. (P1)

Uma valorização de remuneração, de crescimento enquanto carreira e a valorização [por parte] dos demais, dos que estão fora da residência. (P7)

Como também valorização no plano de carreira do hospital. Acho que uma valorização também em termos de carreira, de progressão, acho que isso é bem importante. (P4)

[...] talvez o preceptor de campo, eu acho que a residência tinha que ser uma das carreiras, a residência multiprofissional, tinha que ser uma carreira que ele trilhasse ali dentro do hospital. O preceptor de campo, ter contratações para a residência. (P3)

\section{[...] tem alguns serviços que já conseguem justificar a contratação. (P4)}

Teve alguns preceptores da emergência que já entraram, por causa disso. (P7)

Até o reconhecimento de uma carreira de preceptor seria interessante, porque isso dá força. Se não, nós somos os trabalhadores quebrando o galho, ali, da forma que dá, aqui e ali, quebrando o galho na assistência, no cuidado e na formação de outros. (P4)

Em relação aos sonhos possíveis para os residentes, os preceptores apresentam a garantia de um plano de carreira para os residentes dentro do SUS:

Meu sonho é que se tivesse uma certa garantia sobre isso... principalmente nesse resultado, pós residência, como se fosse um plano de carreira dentro do SUS. Não que ele fique, mas que ele possa ficar, por exemplo, tem uma vaga para professor de educação física lá em Guaranguaduva, no meio do RS, quer ir? Ele vai poder optar ou não. Uma coisa mais ou menos parecida com o plano dos juízes: vou ficar primeiro aqui nesse lugar que é menor, depois eu vou 
poder optar por outro lugar maior. Ou da formação dos residentes, do futuro deles, depois de egressos, que eles já pudessem ingressar no trabalho do SUS, com garantia. Tudo isso seria maravilhoso; mas, depende muito mais de outras coisas. (P4)

Seria legal se a gente combinasse com outra residência, a valorização profissional, o futuro do residente egresso voltando para a rede do SUS. (P7)

Sim, por isso que até nós trouxemos como um sonho que a residência garantisse um plano de carreira, garantisse que este profissional que está sendo formado para o SUS com bolsa, com qualificação ficasse ou tivesse prioridade para continuar a sua atuação no SUS. (P4)

Esse plano de carreira para o residente sinaliza a preocupação que os preceptores destinam à formação que a Residência Multiprofissional oportuniza, uma formação para o trabalho no SUS articulada aos princípios desse sistema. Ainda, os preceptores sonham que os residentes tenham boa inserção no mercado de trabalho.

A maioria dos residentes, pelo menos os residentes com quem estabeleci uma relação fora da residência e que são meus amigos hoje, a maioria, quase 100\%, consegue se colocar no mercado de trabalho. Seja em empresas privadas, seja em empregos públicos, seja em mestrados, seja até em outros cargos profissionais que não necessariamente na área da saúde. (P2)

E sempre tem vaga [...] o pessoal nos liga para ver se tem pessoal se formando. [...] nós formamos para o SUS, mas eles são absorvidos também pelo mercado de trabalho particular. (P6)

Além dos sonhos para si e para os residentes, os preceptores apresentam os sonhos relacionados à proposta do RMS. Dentre os sonhos, relatam sobre a infraestrutura adequada, professores exclusivos para o Programa e a integração da Residência Médica e a Multiprofissional:

O meu sonho tem a ver com a RMS em relação à infraestrutura desta. Eu sonho que a RMS pudesse ter salas de aulas, recursos com multimídia, laboratórios de informática. Laboratórios de práticas também, uma coisa que a gente fez na Farmácia são simulações realísticas. (P5)

Com professores contratados com dedicação exclusiva para a residência, para que as aulas de campo e de núcleo [...] pudessem ter esse respaldo dos professores. (P5)

Mas o meu sonho primeiro era a integração com a residência médica, este eu acho que é o top, porque [como] tu falar em equipe sem esta integração? Excludente, né? (P3)

E nesse sonho tem também algo que eu não sei se é uma característica que é do hospital ou se é de outras residências multiprofissionais. [...] seria uma integração com a residência médica, porque, às vezes, tudo acontece muito descolado, e descolado em todos os sentidos. Às vezes, nós não conseguimos ter o residente multiprofissional com o médico, porque o médico tem aula toda semana, um de tarde, outro tem de noite... (P4) 
A integração com a residência médica é um sonho mesmo, porque isso é algo que a gente depende deles. (P7)

Na perspectiva de qualificar a RMS, os preceptores refletiram sobre os estágios vivenciais, sendo uma possibilidade de enriquecimento de experiência desses atores que estão em formação. No caso de P2, esse teve a oportunidade de experimentar quando era residente e perceber o quanto esses estágios contribuíram para um tipo de formação crítica e ampliada da atenção em saúde:

Quanto ao meu sonho, são os estágios de vivências [...] Trata-se de uma atividade onde todos os atores envolvidos em uma ênfase frequentam um serviço de uma cidade pioneira, por exemplo, um serviço de saúde mental, vivenciando de forma grupal as características que levaram esta cidade e ao serviço ao grau de excelência nessa área. [...] Eu tive a oportunidade de fazer o estágio vivência, a minha residência foi na UFRGS. [...] nós ficamos duas semanas conhecendo a rede de saúde mental de Campinas, que é referência, tem o mesmo PIB e o mesmo número de habitantes que Porto Alegre, porém eles têm uma rede (rede de atenção a saúde mental) muito melhor. Enfim, tem um histórico bem bacana. E foi bem legal, uma oportunidade impar! (P2)

É bem isso que o colega falou agora, eu até não usei 'estágio vivência' porque eu não tinha conhecimento [dessa experiência]. Mas, eu penso que seria super proveitoso para as residências em si se houvesse um intercâmbio dos residentes dentro dos itinerários. Por exemplo, no adulto crítico, nós temos uma carência de, por exemplo, pacientes queimados, pacientes em trauma, e poderia ter, dentro do itinerário, um período que os nossos residentes pudessem passar em locais onde tivessem estas características, por exemplo, o HPS, Hospital Cristo Redentor, e eles, de lá, viessem para cá. Fazer esta troca, que os programas de residência se conversassem, claro que, evidente, dentro dos seus campos, que eu acho que seria super proveitoso. (P7)

Além disso, os preceptores trazem a possibilidade de realizar intercâmbios dos residentes nos diferentes itinerários, sendo compreendido como experiências externas ao contexto local a que está vinculado sua RMS. Assim, poderia conhecer outras realidades e, consequentemente, oxigenar o conhecimento local com novas experiências.

Os resultados apresentaram que o grupo de preceptores problematizou diversas possibilidades, pensando em melhorias para a Residência Multiprofissional como um todo. No entanto, sabe-se que os sonhos destacados até o momento dependem também de outras instâncias para a sua viabilidade. Assim, eles foram instigados a buscar sonhos viáveis, que são aqueles que podem ser exequíveis por meio de iniciativas/da intervenção de preceptores na RMS. O primeiro sonho possível se refere às ações entre as ênfases que os preceptores atuam:

- O que eu acho, que foi colocado aqui e que me pareceu mais viável, ainda, são as ações inter ênfases [entre as ênfases da RIMS], que seria alguma coisa que a gente poderia fazer. (P7)

- Exato. Eu digo que, para ter este planejamento destas ações... porque, quando tu vês, tu entras no automático, tu sais para atender paciente, tu tens que resolver aquilo, tens que dar conta de uma reunião, e outras coisas que também são estratégias e que te exigem tempo e não sobra tempo! e então, tu vais fazendo [sem refletir]. (P3)

Eu vejo assim, do que foi visto, estas ações inter ênfases ainda podem ser viáveis, de nós começarmos a ter esse pensamento, do que tem de comum entre os campos e trazer para os nossos itinerários. (P7) 
Da integração inter ênfases também pode acontecer, porque é algo mais palpável. Porque os exemplos que acontecem foram daí que nós trouxemos. Eles acontecem de forma isolada e com iniciativas de grupos: ah, aconteceu que... por acaso surgiu a ideia de que vinha acontecendo na Cardiologia, mas ainda são ideias isoladas. (P7)

Esse sonho foi compartilhado por todo o grupo, por meio das reflexões realizadas a cada encontro, sendo que nesses momentos, os profissionais observaram que deveriam realizar ações integradas entre eles, nos diferentes núcleos profissionais que compõem cada área de atenção, englobando os preceptores para pensarem ações coletivas. Além disso, visitas às diferentes áreas da RMS, mapas de atuação dos residentes foram sonhos que foram sendo construídos coletivamente, a fim de promover uma formação interprofissional.

[...] as residentes querem se visitar para ver como é o controle de infecção. Tem muita curiosidade de saber, dos residentes, o que se faz lá, o que se faz na Álvaro Alvim, tem muita fantasia. Então, porque nós não estabelecemos isso dentro dos nossos itinerários para que possamos propor as ações inter ênfases em conjunto? (P2)

Eu concordo com o colega. Eu acredito que, para nós fazermos estas ações inter ênfases, nós teríamos que fazer um mapa dos itinerários, saber onde que os residentes estão próximos para fazer as ações. Então pensar em quando o Adulto Crítico vai discutir tal tema e o Controle de Infecção é implicado com este tema. (P1)

Os preceptores também propuseram o planejamento coletivo das aulas teóricas e de outras atividades, sendo considerada uma potente estratégia para fortalecer os diferentes campos de atuação dos residentes e promover a integração das ações da RMS.

Quem sabe nós planejamos as aulas juntos? (P7)

- Sim, e uma aula de campo com dois campos e não com um campo só. Porque em nenhum lugar diz que tem que ser de um campo só, específico (P1)

-Esse ano nós fizemos atividades assim. (P3)

- Ficaria muito legal! Muito interessante. (P3, P5 e P6)

[...] eu coloquei em relação à atividades teóricas [nos sonhos], mas, acho que não! Poderia ser em práticas como vocês estão falando, que eu acho que nós poderíamos fazer um planejamento e compartilhar esse planejamento, e discutir e pensar o que eu poderia fazer junto com o outro campo ou o que eu poderia fazer com os outros núcleos. (P3)

Na reunião passada, surgiu esse assunto. Essa coisa de as residências se conversarem, de as atividades se conversarem e ter uma integração entre os preceptores. (P7)

Assim, os sonhos estão voltados para a valorização da função do preceptor, para o aproveitamento do residente como recurso humano para o SUS, para o investimento e qualificação da estrutura pedagógica dos programas, para a ampliação dos campos de formação do residente, estimulando-se as trocas interprofissionais e entre as diferentes ênfases dentro de um mesmo programa, ou ainda entre diferentes programas de residência multidisciplinar em saúde (PRMS). 


\section{Discussão}

Esse artigo contempla os sonhos de um grupo de preceptores para a Residência, ao imaginarem as melhores práticas que poderiam ser realizadas no PRMS. Os resultados evidenciaram que o grupo buscou sonhar em duas amplitudes, igualmente importantes, sendo compreendidas como os sonhos possíveis e os sonhos viáveis.

Os sonhos possíveis, de acordo com Freire (2011) são aqueles que partem da compreensão da história como possibilidade e não determinismo, aqueles relacionados à utopia dos que não se adequam aos fatos como dados. Para Freire, os sonhos assumem conotação política e "uma das tarefas políticas que devemos assumir é viabilizar os sonhos que parecem impossíveis" (Freire, 1991, p. 126). Nesse sentido, Paro, Ventura e Silva (2019) destacam o compromisso da educação na formação de sujeitos críticos e criativos que, compreendendo sua historicidade, reconheçam sua capacidade de intervir no mundo e, dessa forma, transformá-lo.

Dentre esses sonhos, os preceptores trouxeram a valorização financeira do preceptor, a criação de um plano de carreira e que os demais profissionais e os serviços os valorizem de acordo com o seu papel pedagógico no PRMS.

A valorização financeira é um elemento que implica no reconhecimento do preceptor, visto que esses são atores fundamentais no cenário dos PRMS. Esse aspecto foi abordado por autores que problematizam o papel e argumentam em favor da qualificação da preceptoria, em vistas a conquistar uma carga horária direcionada para as atividades, o incentivo financeiro e ações voltadas à formação dos preceptores. Sabe-se que a não previsão de carga horária específica, direcionada ao atendimento do residente, pode gerar sobrecarga laboral dos preceptores, especialmente pelo acúmulo de funções demandadas (assistência e formação) (Milanesi, Caregnato \& Canabarro, 2019).

No entanto, em relação ao apoio financeiro aos profissionais preceptores, outro estudo mostra que há divergências de opiniões acerca dessa reivindicação. Por um lado, a inserção dos profissionais em hospitais escola, já antevê dentre suas atividades a formação e a aprendizagem de estudantes. Já por outro lado, visto a função de preceptoria estar agregada ao horário de trabalho e gerar essa sobrecarga, seria importante haver um subsídio financeiro (Silva \& Natal, 2019).

Em estudo realizado em uma Residência Multiprofissional, os participantes identificaram que a ausência de auxílio financeiro para a supervisão dos residentes funciona como um fator de desmotivação para os preceptores (Melo, Queluci \& Gouvêa, 2014). No entanto, os participantes da pesquisa descobriram que, visto ser em um hospital de ensino, a atuação como preceptor consta no estatuto do servidor, recebido pelos profissionais em sua admissão na instituição, sem qualquer menção à gratificação financeira. Importante destacar, que a Lei 8080, que cria e regulamenta o Sistema Único de Saúde, determina que os serviços que constituem o SUS devem ser campo de prática para atividades de ensino e pesquisa. Nessa direção, essa Lei destaca a necessidade de diálogo entre instituições de ensino e serviços de saúde com vistas a definir normas e propor prioridades, métodos e estratégias para formação e educação permanente dos profissionais (Brasil, 1990).

Para equilibrar os movimentos de divergência, acredita-se que é necessário reconhecer a educação como um ato político, como defende Freire (2015) e desenvolver espaços de pactuações e diálogos, para que os envolvidos em nível de gestão possam tomar conhecimento e levar em consideração as necessidades dos preceptores. Assim, esses espaços permeados pelo diálogo, possibilitariam a construção de estratégias contextualizadas, considerando a singularidade dos atores (Freire, 2014).

À exemplo, em um modelo de Residência que proporcionasse ao preceptor tempo em sua agenda, poderia resultar em maior disponibilidade para atividades de formação. Assim, uma alternativa seria definir o tempo que o preceptor poderia investir em outras atividades que não envolvem a preceptoria, sem alterar o acompanhamento pedagógico dos residentes e a organização e o planejamento das atividades de formação (Castells, Campos \& Romano, 2016).

A possível criação de um plano de carreira para os preceptores também foi evidenciada nos resultados, sendo que, segundo os participantes da pesquisa, essa estratégia fortaleceria a progressão profissional. Em vistas disso, ações 
interministeriais vem sendo desenvolvidas em prol da construção formativa na saúde e em concordância com a EPS, como a Portaria n 1.124, de agosto de 2015, que instrui as diretrizes para a criação dos Contratos Organizativos de Ação Pública de Ensino-Serviço (COAPES), nas três esferas do governo, em busca da promoção da formação dos preceptores e apoio nas ações de valorização dessa atividade. Medidas como a gestão de carga horária, incentivos para qualificação profissional, progressão funcional, de carreira, dentre outras possibilidades, são previstas pelo Contrato, visando a qualificação e aperfeiçoamento dos profissionais do serviço (Brasil, 2015).

Outro aspecto que implica na valorização do preceptor seria sua participação mais ativa no planejamento das atividades teóricas e teórico-práticas a serem desenvolvidos no PRMS (Conceição-Silva \& Brotto, 2016) e na seleção mais pertinente de temas que possam impactar na realidade local.

O conhecimento não é apenas cognitivo, ele é uma prática, não sendo possível a separação entre teoria e prática. Não é "o que é", e sim "como é", e esse "como" é o conhecimento (Freire, 2015). O saber do preceptor é o saber rico da experiência, vivenciada no dia a dia. Valorizar o saber deste profissional é valorizar o conhecimento advindo da experiência. Para Freire (2015), homens e mulheres se tornam seres roubados, à medida que não forem autorizados a participar da construção do amanhã. No entanto, pensar o amanhã requer a definição de um projeto, o qual tem no sonho, na utopia e na esperança sua orientação. Por outro lado, não é possível pensar o amanhã, "sem que nos achemos em processo permanente de 'emersão' do hoje, 'molhados' do tempo que vivemos, tocados por seus desafios, instigados por seus problemas [...].' (Freire, 1997, p 671)

Uma aproximação maior entre os professores vinculados às universidades e os preceptores do serviço pode ser vista como uma estratégia de corresponsabilização, e poderia diminuir as dificuldades do processo ensino-aprendizagem, compartilhando assim as ações entre serviço, preceptor e tutor (Autonomo et al., 2015). Se os preceptores desejam valorização do papel pedagógico e professores exclusivos para a RMS, uma proposta poderia ser preparar os preceptores para que eles também tivessem atividades relacionadas ao ensino, incentivando-os a buscarem qualificações por meio de mestrado e doutorado acadêmico e/ou profissional. Diante disso, o desafio seria garantir formação, ampliar acesso a qualificação e ter respaldo da gestão para isso.

Em relação à valorização, também é necessário proporcionar condições para que esse profissional possa se sentir mais participativo na Residência. Enquanto não há condições de valorização financeira, pensar em outras estratégias que incentivem esse profissional a participar da RMS pode ser um caminho em direção aos sonhos. Ceccim e colaboradores (2018) já referem que os profissionais dos serviços não possuem incentivo financeiro para a função de preceptor, nem por parte dos programas de residência nem por parte da gestão dos serviços; assim, em muitas situações, esses resistem em assumir função pedagógica, o que implica dificuldade de acompanhar e orientar os residentes.

Outras estratégias de valorização poderiam incluir a garantia de carga horária reservada para atuação junto ao programa de residência, para participação em atividades de pesquisa, o incentivo para que o preceptor participe de bancas ou como coorientador de trabalhos de conclusão da residência.

Em relação aos sonhos possíveis dos preceptores para os residentes, o plano de carreira dos residentes para o SUS pode ser uma forma de qualificar e oxigenar os serviços de saúde, valorizando essa estratégia de formação pela imersão na realidade. Em uma pesquisa sobre motivação para cursar a Residência, todos os residentes ingressaram no programa devido à necessidade de especialização exigida pelo mercado de trabalho (Magnabosco et al., 2015). Esse dado mostra a significativa incorporação dos residentes no mercado de trabalho e a preocupação que os preceptores destinam à formação que os PRMS oportunizam, ou seja, uma formação para o trabalho no SUS articulada aos princípios desse sistema.

Evidenciou-se o estágio de vivência, o intercâmbio dos residentes entre as diferentes áreas da RMS e o plano de carreira para os residentes. O estágio de vivência parte de experiência positiva que um dos preceptores vivenciou e, a partir 
disso, acredita-se na potencialidade dessa estratégia no PRMS, sendo essa já aderida em outros programas, com a participação de residentes e preceptores (Uchôa-Figueiredo, Rodrigues, \& Dias 2016).

Além disso, o intercâmbio entre os residentes nas diferentes áreas da RMS mostra que a integração é primordial. Esse intercâmbio proporcionaria uma formação para além do cenário que sedia o contexto da RMS. Esse sonho está relacionado à visita aos cenários extra hospitalares que teriam a possibilidade de expansão da formação do residente.

Assim, acredita-se na importância da articulação de coordenadores, gestores, tutores e preceptores, para traçar uma proposta de ensino-aprendizagem no serviço, por meio de estratégias que possibilitem ao residente uma imersão nos locais de produção do cuidado e colocando, aos trabalhadores, o exercício contínuo de análise do sentido das práticas, propiciando o estabelecimento de ações questionadoras e de ressignificação (Dias et al., 2016).

As práticas integrativas entre as ênfases da RMS representam o sonho compartilhado por todo o grupo. Para Ana Freire (2004) não é possível sonhar e realizar o sonho se não se comunga este sonho com as outras pessoas. Por isso, entre os sonhos elencados pelos preceptores, destacamos a categoria dos sonhos viáveis, compreendidos como aqueles que, além de serem possíveis, relacionam-se com possibilidades e iniciativas que podem ser viabilizadas a curto prazo por ações da micropolítica, por rearranjos que dependem mais da atitude e do desejo de mudança de cada um. Os resultados mostram que, por meio das reflexões que os preceptores iam realizando a cada encontro, perceberam que deveriam realizar práticas integradas entre eles, que envolvessem diferentes núcleos profissionais e englobassem preceptores das diferentes áreas para pensarem ações coletivas, multiprofissionais e interprofissionais.

Assim, a RMS pode ser considerada uma estratégia de Educação Interprofissional em Saúde (EIS). Na EIS, estudantes de duas ou mais profissões aprendem de forma interativa e engajada, com os membros do grupo, sobre suas profissões. Para isso, há um compromisso entre os sujeitos envolvidos em buscar a resolução de problemas e a negociação nas tomadas de decisão em uma perspectiva colaborativa (Torres et al., 2019). Freire (1997) destaca que, conceber a história como possibilidade, pressupõe a capacidade de o ser humano observar, pensar, conhecer, avaliar, decidir, optar, romper, transgredir, ser responsável, acreditar, sonhar, fazer profecia.

O profeta é o que, fundado no que vive, no que vê, no que escuta, no que percebe, no que intelige, a raiz do exercício de sua curiosidade epistemológica, atento aos sinais que procura compreender, apoiado na leitura do mundo e das palavras, antigas e novas, à base de quanto e de como se expõe, tornando-se assim cada vez mais uma presença no mundo à altura do seu tempo, fala, quase adivinhando, na verdade, intuindo, do que pode ocorrer nesta ou naquela dimensão de experiência histórico-social. (Freire, 1997, p. 671-2).

Para Paro, Ventura e Silva (2020), sonhar coletivamente sonhos possíveis gera compromisso com a concretização de possibilidades. Ao se relacionarem entre si, mediados pelo mundo, os seres humanos constroem não apenas saberes, mas também as condições e relações necessárias para estar no mundo e para viabilizar a construção de seus sonhos. "A distância entre o sonhado coletivamente e o realizado cotidianamente pelos sujeitos é um espaço a ser ocupado pelos atos criadores" (p. 15), à medida que esses assumem os riscos implicados nas mudanças e o protagonismo para realizar as rupturas necessárias. Ademais, pode ser uma importante estratégia para formar profissionais aptos para o trabalho em equipe, prática essencial para a integralidade do cuidado (Casanova, Batista \& Ruiz-moreno, 2015). É nesse caminho que o encontro entre profissionais, residentes e usuários, onde se desenvolve a produção do cuidado, configura-se como cenário para a produção pedagógica, permitindo a troca de saberes afetivos e cognitivos (Silva et al., 2016).

Além disso, ao considerar que o eixo central dos PRMS é a EPS, essa opção política-pedagógica solicita sujeitos ativos, reflexivos, compromissados e protagonistas de ações contextualizadas, fontes para reflexão e aprendizado. A partir 
desse princípio, abandona-se o conceito de formação como processo de atualização descontextualizada do profissional, para adotar uma formação que busque construir conhecimentos a partir da prática e da reflexão sobre a mesma (Daussy, 2014). Observa-se que a EPS, como orientadora dessa proposta, possibilita o diálogo entre os diferentes saberes dos atores da Residência em busca de novos sonhos e possibilidades para a formação, assistência e gestão em saúde.

\section{Considerações Finais}

Com o objetivo de analisar os sonhos dos preceptores frente às práticas que poderiam ser implementadas no Programa de Residência Multiprofissional, observamos que os preceptores trouxeram, num primeiro momento, o desejo de maior reconhecimento da Residência (ou RMS) como espaço de formação, incluindo a valorização das atividades realizadas pelos preceptores, além, e plano de carreira no SUS para os para os residentes que realizaram essa especialização.

Além disso, ao colocar em debate a fase sonhos, observamos que os preceptores imaginaram o que seriam as melhores práticas para a Residência Multiprofissional, destacando estágios vivências, a integração da residência médica com a residência multiprofissional, maior participação no planejamento das atividades e na definição dos campos de prática, entre outras.

A partir dessas práticas, discutiram a possibilidade de os sonhos se tornarem realidade. Essa fase foi relatada como a mais expressiva, pois eles tiveram a oportunidade de explorar suas esperanças e desejos, visualizando a constituição de um projeto coletivo para o futuro.

Os resultados da pesquisa possibilitam reflexões frente aos desafios para desenvolver uma formação e seu planejamento de forma dialógica e democrática no qual a formação reconheça a autonomia dos sujeitos, permitindo expressão do saber e das experiências dos preceptores, assim como a reflexão crítica quanto a sua atuação nas Residências Multiprofissionais. Nessa perspectiva, a formação assume o compromisso de promover a natureza humana dos sujeitos envolvidos, como seres em permanente busca do ser mais, estimulando e apoiando sua inserção e intervenção no mundo de forma crítica, criativa e corresponsável.

Ao dialogar sobre os sonhos dos (e com os) preceptores entende-se que foi possível, minimamente, projetar o futuro em movimento. Entre sonhos possíveis e viáveis, a pesquisa coloca em evidência a vontade e o engajamento coletivo para a concretização de uma utopia compartilhada em nível nacional, ou seja, a construção de um "SUS que dá certo", e que tem na RMS e seus protagonistas a esperança de criar e desenvolver possibilidades que viabilizem a sua realização.

Como continuidade do presente estudo, sugerimos a realização de outras pesquisas que ofereçam experiências inovadoras para a valorização do preceptor e/ou evidenciem se há impacto desse modelo de formação em cenários que acolhem os profissionais especialistas oriundos de RMS. Estudos que promovam estratégias para o desenvolvimento de capacitações formais e que forneçam subsídios para um trabalho educativo, fortalecendo a comunicação entre academia e serviço ainda são escassos. Além disso, a avaliação da implementação de planos de carreira aos preceptores das RMS e de ações de intercambialidade entre residentes e preceptores são ideias a serem exploradas e que podem impactar positivamente na qualidade das ações de ensino e serviço no SUS.

\section{Referências}

Arnemann, C. T. (2017). Educação permanente em saúde no contexto da residência multiprofissional: estudo apreciativo crítico. 263f. Tese (Doutorado em Enfermagem) - Programa de Pós Graduação em Enfermagem da Escola de Enfermagem da Universidade Federal do Rio Grande do Sul, Porto Alegre, Rio Grande do Sul.

Arnemann, C. T. et al. (2018). Práticas exitosas dos preceptores de uma residência multiprofissional: interface com a interprofissionalidade. Interface (Botucatu), 22(2), 1635-1646.

Arnemann, C. T.; Gastaldo, D., \& Kruse, M. H. L. (2018). Pesquisa Apreciativa: características, utilização e possibilidades para a área da Saúde no Brasil. Interface - Comunicação, Saúde, Educação, 22(64),121-131. 
Autonomo, F. R. O. (2015). A Preceptoria na Formação Médica e Multiprofissional com Ênfase na Atenção Primária-Análise das Publicações Brasileiras. Revista Brasileira de Educação Médica, 39(2), 316-327.

Brasil. Conselho Nacional de Saúde. Resolução no 466, de 12 de dezembro de 2012. Aprova diretrizes e normas regulamentadoras de pesquisas envolvendo seres humanos e revoga também as Resoluções n $n^{\circ}$ 303/2000 e nº 404/2008. Diário Oficial da União, 13 de junho de 2013, seção 1, p. 59.

Brasil. Lei $\mathrm{n}^{\circ}$ 8.080, de 19 de setembro de 1990. Dispõe sobre as condições para a promoção, proteção e recuperação da saúde, a organização e o funcionamento dos serviços correspondentes e dá outras providências. Diário Oficial da União, Brasília, DF, 20 set. 1990. p. 018055.

Brasil. Ministério da Saúde. Portaria Interministerial n ${ }^{\circ}$ 1.124, de 4 de agosto de 2015. Institui as diretrizes para a celebração dos Contratos Organizativos de Ação Pública Ensino-Saúde (COAPES), para o fortalecimento da integração entre ensino, serviços e comunidade no âmbito do Sistema Único de Saúde (SUS). Diário Oficial da União, nº 148, 5 de agosto de 2015, seção 1, p. 193-196.

Brasil. Ministério da Saúde. Portaria $\mathrm{n}^{\circ} 754$, de 18 de abril de 2012. Altera a Portaria $\mathrm{n}^{\circ}$ 1.111/GM, de 5 de julho de 2005 que fixa normas para a implementação e a execução do Programa de Bolsas para a Educação pelo Trabalho. Diário Oficial da União, nº 77, p. 47, 20 abril de 2012.

Casanova, I. A., Batista, N. A., \& Moreno, L. R. (2018). A Educação Interprofissional e a prática compartilhada em programas de residência multiprofissional em Saúde. Interface - Comunicação, Saúde, Educação, 22(1), 1325-1337.

Castells, M. A., Campos, C. E. A., \& Romano, V. F. (2016). Residência em Medicina de Família e Comunidade: Atividades da Preceptoria. Revista Brasileira de Educação Médica, 40(3), 461-469.

Ceccim, R. B., et al. (2018). Formação de formadores para residências em saúde: corpo docente-assistencial em experiência viva. Rede Unida.

Conceição-Silva, L., \& Brotto, M. E. (2016). Residência Multiprofissional em Saúde: o olhar dos preceptores sobre o processo de ensino-aprendizagem. Revista de Políticas Públicas, 20(2), 1-1.

Cooperrider, D. (1986). Appreciative inquiry: toward a methodology for understanding and enhancing organizational innovation [dissertation]. Cleveland: Western Reserve University.

Daussy, M. F. S. (2014). Contribuições da prática reflexiva às estratégias de Educação Permanente em Saúde nos núcleos de apoio à saúde da família. 142f. Dissertação (Mestrado em Saúde Coletiva) - Programa de Pós-Graduação em Saúde Coletiva, Florianópolis, Santa Catarina.

Denzin, N. K., Lincoln, Y. S. (2000). Handbook of qualitative research. (2a ed.). Sage.

Dias, I. M. A.V., Pereira, A. K., Batista, S. H. S. S., \& Casanova, I. A. (2016). A tutoria no processo de ensino aprendizagem no contexto da formação interprofissional em saúde. Saúde Debate, 40(111), 257-267.

Ferreira, F. Das C., Dantas, F.C., \& Valente, G.S.C. (2018). Saberes e competências do enfermeiro para preceptoria em unidade básica de saúde. Revista Brasileira de Enfermagem, 71, 1564-1571.

França, T., Magnago, C., Santos, M. R., Belisário, S. A., \& Silva, C. B. G. (2018). PET-Saúde/GraduaSUS: retrospectiva, diferenciais e panorama de distribuição dos projetos. Saúde em Debate, 42, 286-301.

Freire, Ana Maria (Org). (2004). Pedagogia da tolerância. UNESP.

Freire, P. (1991). A educação na cidade. Cortez.

Freire, P. (2011). Pedagogia da esperança. (22a ed.), Paz e Terra.

Freire, P. (2014). Educação e mudanças. Paz e Terra.

Freire, P. (1997). Denúncia, anúncio, profecia, utopia e sonho. In.: Brasil. Senado Federal. O livro da profecia: o Brasil no Terceiro Milênio. Brasília, Coleção Senado, 1, 671-686.

Freire, P. (2015). Algumas reflexões em torno da utopia. In.: Freire, P. Pedagogia dos sonhos possíveis. Paz e Terra.

Girard, G. P., Sardinha, D. M., Nascimento, M. H. M. N., Teixeira, R. C., Borges, S. C. R. (2019). Interdisciplinaridade no ensino prático em Residência Multiprofissional em Saúde. Revista Eletrônica Acervo Saúde, 11(7),

Magnabosco, G., Haddad, M. C. L., Vannuchi, M. T. O., Rossaneis, M. A., \& Silva, L. G. C. (2015). Opinião de egressos sobre o curso de residência em gerência dos serviços de enfermagem. Semina: Ciências Biológicas da Saúde, 36(1), 73-80.

Melo, M. C., Queluci, G. C., \& Gouvêa, M. (2014). Preceptoria de enfermagem na residência multiprofissional em oncologia: um estudo descritivo. Online Brazilian Journal of Nursing, 13(4), 656-666.

Milanesi, R., Caregnato, R. C. A, \& Canabarro, S. T. (2019). Residência Multiprofissional em Saúde: vivência do ser preceptor na atenção ao paciente crítico. Research, Society and Development, 8(4), e4284871.

Paro, C. A., Ventura, M., \& Silva, N. E. K. (2020). Paulo Freire e o inédito viável: esperança, utopia e transformação na saúde. Trabalho Educação e Saúde, $18(1), \mathrm{e} 0022757$.

Ribeiro, K. R. B., \& Prado, M. L. (2013). A prática educativa dos preceptores nas residências em saúde: um estudo de reflexão. Revista Gaúcha de Enfermagem, 34(4), 161-165.

Ribeiro, P. K. C., Firmo, W da C. A., Sousa, M. H. S. L., Figueiredo, I. A., \& Pacheco, M. A. B. (2020). Os profissionais de saúde e a prática de preceptoria na atenção básica: assistência, formação e transformações possíveis. Journal of Management \& Primary Health Care, 12, 1-18. 
Research, Society and Development, v. 10, n. 7, e27010716079, 2021

(CC BY 4.0) | ISSN 2525-3409 | DOI: http://dx.doi.org/10.33448/rsd-v10i7.16079

Silva, C. T., Terra, M. G., Kruse, M. H. L., Camponogara, S., \& Xavier, M. S. (2016). Residência multiprofissional como espaço intercessor para a educação permanente em saúde. Texto Contexto Enfermagem, 25(1), e2760014.

Silva, L. S., \& Natal, S. Residência multiprofissional em saúde: análise da implantação de dois programas pela Universidade Federal de Santa Catarina. Trabalho Educação e Saúde, 17(3), e0022050.

Torres, R. B. S., Barreto, I. C. H. C., Freitas, R. W. J. F., \& Evangelista, A. L. P. (2019). Estado da arte das residências integradas, multiprofissionais e em área profissional da Saúde. Interface - Comunicação, Saúde, Educação, 23(1), e170691.

Trajkovski, S., Schmied, V., Vickers, M., \& Jackson, D. (2013a). Implementing the 4D cycle of appreciative inquiry in health care: a methodological review. Journal of Advanced Nursing, England, 69(6), 1224-1234.

Trajkovski, S., Schmied, V., Vickers, M., \& Jackson, D. (2013b). Using appreciative inquiry to transform health care. Contemporary Nurse, United States, 45(1), 95-100.

Uchôa-figueiredo, L. R., Rodrigues, T. F., \& Dias, I. V. (Org.). (2016). Percursos Interprofissionais: formação em serviços no programa residência multiprofissional em atenção à saúde. Rede Unida, p. 77-105. 